\section{Digital mobile telephones and interference of ophthalmic equipment}

\author{
GS Ang ${ }^{1}$, P Lian ${ }^{1}$, WS Ng${ }^{1}$, I Whyte ${ }^{1}$ and $\mathrm{JM} \mathrm{Ong}^{2}$
}

Keywords: mobile telephone; cell phone;

electromagnetic interference

Aim To assess the effect of mobile telephone electromagnetic interference on electronic ophthalmic equipment.

Methods Prospective audit with mobile telephones placed at distances of $3 \mathrm{~m}, 1 \mathrm{~m}$, and $30 \mathrm{~cm}$ from, and in contact with, electronic ophthalmic equipment. Any interruption or cessation of the function of the ophthalmic device was assessed with the mobile telephones in standby, and in dialling or receiving modes. Any alterations of displayed digital figures or numbers were also assessed. Results A total of 23 electronic ophthalmic devices in two hospital ophthalmology outpatient departments were evaluated. All six mobile telephones used, and $22(95.7 \%)$ of the 23 ophthalmic equipment evaluated had the Conformité Européene (CE) mark. No device showed any interruption or cessation of function. There were no alterations of displayed digital figures or numbers. The only effect of any kind was found with four instruments (1 non-CE marked), where there was temporary flickering on the screen, and only occurred when the mobile telephones were dialling or receiving at a distance of $30 \mathrm{~cm}$ or less from the instruments.

Conclusion This study shows that among the electronic ophthalmic devices tested, none suffered failure or interruption of function, from mobile telephone interference. Although not comprehensive for all ophthalmic equipment, the results question the need for a complete ban of mobile telephones in ophthalmic departments. It highlights the need for a controlled, objectively measured study of the clinically relevant effects of mobile telephones in the ophthalmology outpatient setting. Eye (2007) 21, 29-32. doi:10.1038/sj.eye.6702110; published online 30 September 2005

\section{Introduction}

Mobile telephone bans are widespread in hospitals in the United Kingdom. Apart from being a potential source of irritation, there is a widely perceived assumption that electromagnetic interference (EMI) from mobile telephones will affect the function of electronic equipment, particularly in the intensive care setting. However, a systematic review reveals very little evidence to suggest that this EMI affects most electronic equipment, and even for the equipment that is affected, interference only occurs at a distance of less than $1 \mathrm{~m} .{ }^{1}$

Moreover, under recent legislation, for any manufacturer selling into the EEC, there are statutory requirements that must be fulfilled before the Conformité Européene (CE) mark can be legally applied to the equipment, and one of these is electromagnetic compatibility (EMC) compliance. A CE approved device should be more resistant to interference, and be less capable of producing interference. With these points in mind, it is questionable whether a total ban on mobile telephones in the hospital environment, especially in the ophthalmic setting, is justified.

The Global System for Mobile communication (GSM) currently used by most mobile telephone networks has a carrier frequency of between 900 to 1800 megahertz $(\mathrm{MHz})$. As technology progressed, the Wideband Code Division Multiple Access (WCDMA) system was developed to allow multiple usage and transmission using the same frequency, thus alleviating the problem of ever-increasing demand for wireless communication capacity.
${ }^{1}$ Department of Ophthalmology, Raigmore Hospital, Inverness, UK

${ }^{2}$ Department of Ophthalmology, Norfolk and Norwich University Hospital, Norwich, UK

Correspondence: I Whyte, Department of Ophthalmology, Raigmore Hospital, Inverness IV2 3UJ, UK Tel: +44 1463 705360; Fax: + 441463705673

E-mail: iain.whyte@ haht.scot.nhs.uk

Received: 31 May 2005 Accepted in revised form: 14 August 2005

Published online:

30 September 2005

Proprietary interests/ research funding/ Competing Interests: None

Presentation: Poster-Scottish Ophthalmological Club Meeting, Edinburgh, February 2005 
To date, there has been minimal literature regarding the effect of mobile telephones in the context of electronic ophthalmic equipment. Additionally, the effects of the new third generation (3G) telephones that are being introduced have not been tested yet. The aim of this study is to assess the clinically relevant effect of mobile telephone EMI on electronic ophthalmic equipment in the ophthalmology outpatient setting. In particular, it examines for the potential of failure or interruption of equipment function by the use of mobile telephones.

\section{Materials and methods}

This was a prospective audit evaluating electronic ophthalmic equipment in two hospital ophthalmology outpatient departments (Inverness and Norwich). The six mobile telephones used were divided into two groups, Group 1 and 2. Each group comprised one WCDMA and two GSM mobile telephones of different models and network (Table 1). Mobile telephones in Group 1 were used to test equipment in Inverness; while in Group 2, they were used to test equipment in Norwich.

For each group, each mobile telephone was placed in turn, at distances of $3 \mathrm{~m}, 1 \mathrm{~m}$, and $30 \mathrm{~cm}$ from, and in contact with, the electronic ophthalmic equipment to be tested. Any interruption or cessation of the function of the ophthalmic device was assessed while the mobile telephone was in standby, and in dialling modes. These devices were tested as they were being switched on, and while having one function running. Any alterations of any displayed digital figures or numbers were also assessed.

The ophthalmic equipment studied was divided into two categories. The first category includes non-measuring diagnostic and treatment instruments. The second category includes instruments used for measurements (Tables 2 and 3).

\section{Results}

In all, 23 electronic ophthalmic devices in two hospital ophthalmology outpatient departments were evaluated. Of the ophthalmic instruments evaluated, 22 (95.7\%) and all $(100 \%)$ mobile telephones used, had the CE mark. No device showed any interruption or cessation of function at all the test distances with the GSM or WCDMA mobile telephones. There were no alterations of displayed digital figures or numbers (Tables 2 and 3).

The only effect of any kind was found with four instruments (1 non-CE marked), where there was

Table 1 Mobile telephones used

\begin{tabular}{llll}
\hline Phone model & Network & Functional frequencies & CE mark \\
\hline Group 1 & & & \\
$\quad$ Nokia 3200 & Vodafone & GSM 900/1800 & Yes \\
Ericsson GA628 & UK Cellnet & GSM 900/1800 & Yes \\
Motorola A1000 & 3 Mobile & & Yes \\
Group 2 & & GSM 900/1800 & Yes \\
Nokia 6230 & Orange & GSM 900/1800 & Yes \\
Samsung SGH A800 & Vodafone & GSM 900/1800 and WCDMA & Yes \\
LG 8120 & 3 Mobile & \\
\hline
\end{tabular}

$\mathrm{GSM}=$ Global System for Mobile communication; WCDMA = Wideband Code Division Multiple Access system

Table 2 Effect of mobile telephones on electronic non-measuring instruments

\begin{tabular}{llll}
\hline & CE mark & Phone group & \\
\hline Non-measuring instruments & & & Effect \\
1. Lumenis Aura Nd:YAG Photodisruptor & Yes & One & No effect \\
2. Coherent Novus 2000 Argon Laser & Yes & One & No effect \\
3. Topcon TRC-50EX Retinal Camera & Yes & One & No effect \\
4. Zeiss Humphrey Systems Field Analyzer Model 740 & Yes & One & No effect \\
5. Coherent EPIC Nd:YAG Photodisruptor & Yes & Two & No effect \\
6. Coherent Ultima 2000 SE Argon Laser & Yes & Two & No effect \\
7. Topcon TRC-50IX Retinal Camera & Yes & Two & No effect \\
8. Hitachi HVC20 Anterior Segment Camera & Yes & Two & No effect \\
9. Zeiss Humphrey Systems Field Analyzer II Model 740i & Yes & Two & No effect \\
10. Quantel Medical CineScan S A/B Scan & Two & No effect \\
\hline
\end{tabular}


Table 3 Effect of mobile telephones on electronic measuring instruments

\begin{tabular}{|c|c|c|c|}
\hline & CE mark & Phone group & Effect \\
\hline \multicolumn{4}{|l|}{ Measuring instruments } \\
\hline 1. Mentor Tono-pen XL Tonometer & Yes & One & No effect \\
\hline 2. Nidek LM-990A Autolensmeter Focimeter & Yes & One & No effect \\
\hline 3. Nidek KM-500 Autokeratometer & Yes & One & No effect \\
\hline 4. Nidek US-1800 Echoscan A-scan & Yes & One & No effect \\
\hline 5. Sonomed A 2500 A-scan & None found & One & Flickering on screen \\
\hline 6. Medtronic Tono-pen XL Tonometer & Yes & Two & No effect \\
\hline 7. Takagi LM-50 Alpha Auto Lensmeter & Yes & Two & No effect \\
\hline 8. Zeiss Autorefractor HARK 597 & Yes & Two & Flickering on screen \\
\hline 9. Zeiss Autorefractor Acuitus 5015 & Yes & Two & Flickering on screen \\
\hline 10. Zeiss IOL Master & Yes & Two & No effect \\
\hline 11. Optikon Keratron Corneal Topographer & Yes & Two & Flickering on screen \\
\hline 12. DGH-550 Pachette-2 Pachymeter & Yes & Two & No effect \\
\hline 13. Optikon Altair Pachymeter & Yes & Two & No effect \\
\hline
\end{tabular}

temporary flickering on the screen occurring only when a dialling or receiving mobile telephone was placed at a distance of $30 \mathrm{~cm}$ or less from the instruments. This was in line with other studies showing that mobile telephone interference usually occurred at a distance of under $30 \mathrm{~cm}^{1-4}$

\section{Discussion}

Mobile telephones are intentional radio transmitters and receivers. EMI occurs when the mobile telephone causes an electronic device to act as a radio receiver unintentionally. Mobile telephones alter their power according to signal strength and distance from the nearest base station. Field strengths, and hence, EMI, are strongest at the beginning of an incoming or outgoing call. ${ }^{5}$

To be placed in the EEC market, a medical device must be compliant with the Medical Device Directive 93/42/ EEC. Medical equipment that has the CE mark means that it has been tested for electromagnetic immunity under test conditions according to the European standard EN 60601-1-2, or equivalent. Approved medical devices working in their intended environment should not interfere with other instruments, or suffer failure when exposed to other similarly approved devices.

Similarly, mobile telephones are now required to conform to the Radio and Telecomunication Terminal Equipment (RTTE) Directive 99/05/EEC and be CE approved in order to sell into the EEC. A CE-marked mobile telephone should be compliant with the EMC standards set in EN 50361, and therefore should not interfere with the operation of other electronic instruments.

Our study shows that among the electronic ophthalmic devices tested, none suffered failure or interruption of function, from mobile telephone interference. The findings were true of not only the currently widely available GSM telephones but with the newly introduced 3G WCDMA telephones as well. With mobile telephones having the CE mark in terms of compliance with EMI, it could be proposed that it is as safe for a mobile telephone to be used in the vicinity of medical equipment, similar to that currently imposed on other medical equipment coexisting side by side in hospital.

We concede that this study only assesses gross effects (failure or interruption) on equipment function.

Objectively measuring the electromagnetic field strength of mobile telephones or the sensitivity or accuracy of the electronic measurements was beyond the scope of this study. However, none of the instruments tested were transmitting devices or highly sensitive receiving devices required to detect faint electrophysiological signals, and therefore, are unlikely to be significantly affected by EMI. Moreover, as the power emitted from mobile telephones is relatively low (maximum $2 \mathrm{~W}$ ), it is not likely that there will be an effect if the distance is more than $1 \mathrm{~m}$ away. Nevertheless, our findings, although not comprehensive for all ophthalmic equipment, do question the need for a complete ban of mobile telephones in ophthalmic departments.

The current ban in the UK is partially based on a study conducted in 1997 on older mobile telephones, when the RTTE Directive 99/05/EEC was not yet introduced. The UK Medical Devices Agency found that only $4 \%$ of medical equipment suffered EMI, and recommended that mobile telephones be switched off where sensitive devices, such as ventilators, were used. ${ }^{6}$ As stated by Morrissey, ${ }^{7}$ a complete ban may deny benefits by acting as an obstacle to technology. The use of mobile telephones in the medical environment will become more pertinent in the near future as their capabilities increase. 
Specifically, in addition to their common use as a communications tool, using their new 3G WCDMA capabilities, mobile telephones are being developed as an adjunct in information provision and medical diagnosis.

Proposals for more flexible approaches to mobile telephones, such as allowing mobile telephone usage in controlled and easily accessible areas, ${ }^{7-9}$ are relevant in the ophthalmic setting. There are already suggestions that complete bans have been ignored, especially by healthcare staff. ${ }^{9}$ We agree that mobile telephones should be switched off in areas where highly sensitive devices are in operation, such as the intensive care unit or in theatre. Uncontrolled usage of mobile telephones will cause undue noise, disturbance, and distraction to both clinicians and patients. However, a balanced approach would safeguard the use of sensitive medical equipment while allowing the full capabilities of mobile telephones to be harnessed and applied. Clearly, there is a need for controlled, objectively measured studies of the clinically relevant effects of mobile telephones in the ophthalmology environment. Finally, the telecommunications and medical equipment organisations can assist the aim of achieving this balance by ensuring new equipment that is being developed conform to International Electrotechnical Commission (IEC) standards on expanded EMC for medical devices. $^{10}$

\section{References}

1 Lawrentschuk N, Bolton DM. Mobile phone interference with medical equipment and its clinical relevance: a systematic review. Med J Aust 2004; 181(3): 145-149.

2 Robinson MP, Flintoft ID, Marvin AC. Interference to medical equipment from mobile phones. J Med Eng Technol 1997; 21(3-4): 141-146.

3 Fung HT, Kam CW, Yau HH. A follow-up study of electromagnetic interference of cellular phones on electronic medical equipment in the emergency department. Emerg Med (Fremantle) 2002; 14(3): 315-319.

4 Shaw CI, Kacmarek RM, Hampton RL, Riggi V, Masry AE, Cooper JB et al. Cellular phone interference with the operation of mechanical ventilators. Crit Care Med 2004; 32(4): 928-931.

5 Gilligan P, Somerville S, Ennis JT. GSM cell phones can interfere with ionizing radiation dose monitoring equipment. Br J Radiol 2000; 73(873): 994-998.

6 Electromagnetic compatibility of devices with mobile communications. Device Bulletin Medical Devices Agency DB 9702, 1997.

7 Morrissey JJ. Mobile phones in the hospital: improved mobile communication and mitigation of EMI concerns can lead to an overall benefit to healthcare. Health Phys 2004; 87(1): 82-88.

8 Myerson SG, Mitchell ARJ. Mobile phones in hospitals. BMJ 2003; 326: 460-461.

9 Aziz O, Sheikh A, Paraskeva P, Darzi A. Use of mobile phones in hospital: time to lift the ban? Lancet 2003; 361: 788.

10 Second edition of IEC 60601-1-2. General Requirements for Safety-Collateral Standard: Electromagnetic Compatibility - Requirements and Tests. International Electro-technical Commission September 2001. 